\title{
Concurrent validation of the MABC-2 and Developmental Coordination Disorder Questionnaire-BR
}

\author{
Ana Paula Pietro Nobre Montoro', Renata Capistrano1, Elisa Pinheiro Ferrari², \\ Monalisa da Silva Reis ${ }^{1}$, Fernando Luiz Cardoso ${ }^{2}$, Thais Silva Beltrame ${ }^{1}$
}

DOI: http://dx.doi.org/10.7322/jhgd.110421

\begin{abstract}
Introduction: The Movement Assessment Battery for Children, Second Edition (MABC-2) has been widely used in national literature for the diagnosis of Developmental Coordination Disorder (DCD). The relationship of MABC-2 with the scientific gold standard instrument for DCD, the Brazilian version of the Developmental Coordination Disorder Questionnaire (DCDQ-BR), is not well established and is rather controversial.
\end{abstract}

Objective: The aim of this study was to verify the concurrent validity of the MABC-2 motor battery and the DCDQ-BR, controlled for sex and age group.

Methods: The concurrent validation process took place with the participation of 350 schoolchildren aged 7-11 years from the cities of Florianopolis-SC and Manaus-AM and their parents or guardians. The agreement between instruments was assessed with the Spearman correlation test and simple linear regression using SPSS software version 20.0.

Results: Positive correlation between instruments' scales was found.

Conclusion: This study showed evidence of concurrent validity between MABC-2 and DCDQ-BR, suggesting that MABC-2 can be used as an indicator for developmental coordination disorder.

Keywords: validation; MABC-2; DCDQ-BR; motor performance.

\section{INTRODUCTION}

The study of motor development is a prerequisite for the full understanding of children's evolution, in which movement is an integral part of life $\mathrm{e}^{1}$. Therefore, motor assessment is important and necessary in preschool individuals $^{2}$ and has been explored in several national ${ }^{3-7}$ and international studies ${ }^{8-10}$.

One of the test protocols most widely used in this area to evaluate motor performance is the Movement Assessment Battery for Children - Second Edition (MABC2), developed in the UK to identify motor difficulties in children aged 3-16 years through the following skills: manual dexterity, ball skills, and static and dynamic balance, organized according to each age group ${ }^{11}$. MABC-2 is a widely used tool in both national ${ }^{3-5}$ and international studies $^{8-10}$.

In Brazil, MABC-2 has been used for the diagnosis of developmental coordination disorder (DCD) ${ }^{3-}$

${ }^{5}$. However, this is not a unique tool for assessment of this disorder, but rather of motor problems as a whole. One of the instruments considered the gold standard for diagnosis of DCD is the Developmental Coordination Disorder Questionnaire (DCDQ), developed in Cana$\mathrm{da}^{12}$ for children aged 5-15 years. It is a questionnaire for parents composed of 15 items related to a child's performance in various everyday activities. Questions are designed to assess three categories: motor control during movement, fine/written motor skills, and general coordination. The instrument has been validated in vari-

1 University of the State of Santa Catarina-UDESC / Graduate Program in Human Movement Sciences - PPGCMH Laboratory of / Learning and Development Disorders - LADADE.

2 University of the State of Santa Catarina -UDESC / Graduate Program in Human Movement Sciences - PPGCMH Graduate Program in Education - PPGE / Laboratory of Gender and Sexuality - LAGESC.

Corresponding author: Renata Capistrano. Email: recapis@gmail.com.

Suggested citation: Montoro APPN, Capistrano R, Ferrari EP, Reis MS, Cardoso FL, Beltrame TS. Concurrent validation of the MABC-2 and Developmental Coordination Disorder Questionnaire-BR. J Hum Growth Dev. 26(1): 74-80. Doi: http://dx.doi.org/10.7322/jhgd.110421 Manuscript submitted: Dec 09 2015, accepted for publication Feb 032016. 
ous countries, such as Australia ${ }^{13}$, China ${ }^{14}$, Germany ${ }^{15}$, Israel $^{16}$, Japan ${ }^{17}$, and Brazil ${ }^{18}$. However, the fact that the instrument uses replies provided by parents or guardians, who may not always have the availability or even knowledge to fill out the questionnaire, compels the researcher to use other tools for diagnosis of DCD that do not require active parental participation. Thus, the increasing use of the MABC-2 motor battery for diagnosis of DCD has been observed.

In light of this information, some studies have verified the concordance between the MABC-2 motor battery and the gold standard, $\mathrm{DCDQ}^{19}$. In the Netherlands, authors found a high correlation between DCDQ and MABC-2 in children aged 6-11 years ${ }^{20}$. In China, researchers evaluated 1.823 children and found that the MABC-2 motor battery and DCDQ were correlated, concluding that MABC has good reliability and validity. In Brazil, a pioneer study developed by Capistrano et al. ${ }^{19}$ did not reveal significant congruence between the MABC-2 motor battery and DCDQ-BR. Given this lack of consensus, the present study seeks to provide a basis for growth and assessment consolidation in motor performance. Thus, the aim of the present investigation was to analyze the concurrent validity of the MABC-2 motor battery with DCDQ-BR according to sex and age group.

\section{METHODS}

\section{Study characterization}

This study was conducted as part of a project entitled "Concurrent validation of the MABC-2, according to the Developmental Coordination Disorder Questionnaire Brazil," which was approved by the protocol number 38772214.3.0000.0118.

\section{Participants}

The study included 350 children (175 girls and 176 boys) aged 7-10 years enrolled in public and private elementary schools of Florianópolis - SC and Manaus - AM and their parents or guardians.

Inclusion criteria were age between 7 and 10 years; agreeing to participate in the study; not presenting physical problems that prevented evaluation of the motor performance; returning the free and informed consent form signed by parents or guardians.

\section{Characterization of different environments}

Florianopolis/SC and Manaus/AM were chosen because of their contextual differences. These cities differ in their physical structure and therefore in the academic structure among schools. For example, in the schools of Florianópolis/SC, students have courtyards, playgrounds, indoor courts, swimming pools, and physical education classes three times a week taught by teachers. This set of elements could provide new and diversified motor experiences. In the schools of Manaus/AM, students have only courtyards and twice weekly physical education classes taught by teachers.

\section{Tools}

To evaluate motor performance, the MABC-2, and the Developmental Coordination Disorder QuestionnaireBrazil (DCDQ-BR) were used and presented as follows:

\section{Movement Assessment Battery for Children, $2^{\text {nd }}$ edition}

The MABC-2 is a motor test protocol developed by Henderson $^{21}$ for intervention in children aged 3-16 years with DCD and other motor problems. It consists of a movement battery, a checklist, and a manual. The MABC-2 is organized into three age-specific sections: 3-6 years, 7-10 years, and 11-16 years. The test refers to a series of tasks (manual dexterity, ball skill, and static and dynamic balance), assigned to a value as number of attempts, hits and misses, or time spent to perform the tasks. The test categorizes children according to their level of motor difficulty. The score varies from 1 to 19, and for each value, there is a corresponding percentage that may vary from $0.1 \%$ to $99.9 \%$. A score at or below the fifth percentile is the cutoff point for severe motor difficulties, such as DCD; values between the sixth and fifteenth percentile are considered to indicate risk for the development of motor difficulties; performance at or above the sixteenth percentile indicates that there are no motor difficulties ${ }^{21}$. For this study, only the motor battery with tasks specific for the age group 7-10 years was used, and children were categorized into two categories: defined motor problem (risk for the development of difficulties and motor problems) and normal motor performance (no motor difficulties).

\section{Developmental Coordination Disorder Questionnaire}

DCDQ is a questionnaire for parents, designed to detect DCD in children aged 5-15 years. Created by Wilson $^{12}$, it consists of 15 items divided into 3 categories: motor control, fine/written motor skills, and general coordination. According to the standard protocol for DCDQ administration, parents are instructed to fill out the questionnaire and mark the answers on a Likert scale from 1 to 5 points, which describes the child's performance on that task. The final score is the sum of the scores of each item, which varies from 15 to 75 points. The total score indicates whether the child is in the group with indicative or suspected DCD or probably no DCD, according to the three cutoffs across age groups. In the group aged 5-7 years and 11 months, a score of 0-46 indicates that the child has DCD or suspected DCD while a score of 4775 indicates that the child probably does not have DCD. From the age of 8 to 9 years and 11 months, a score $0-55$ identifies children who have, or are suspected of having, DCD. In the oldest group, 10-13 years and 11 months, a score of $0-57$ indicates that a child has or is suspected of having DCD. In this study, children who have, or are suspected of having DCD, were considered to have a defined motor problem and those who did not were considered to have normal motor performance.

\section{Procedures}

Motor assessments were individually performed during physical education classes in the period from Sep- 
tember to November 2014 in educational institutions. Students were assessed in a large room with free space, which allowed researchers to conduct the whole test protocol in the same place; this was designed to reduce potential interference. After application of the battery, parents or guardians received a printed copy of the DCDQ-BR questionnaire with a letter explaining how to fill out the instrument and how to contact the researchers in case of further questions.

\section{Statistical analysis}

Data were tabulated in the Statistical Package for Social Sciences (SPSS) ${ }^{\circledR}$ software, version 20.0. To characterize data, descriptive statistics were used to compare means of relative and absolute frequencies.

The concurrent validity of MABC-2 and DCDQ-BR by sex and age group was assessed using the Spearman correlation test. The reference values for this analysis were as follows: below 0.40 , weak correlation; between 0.40 and 0.59 , moderate correlation; between 0.60 and 0.80 , good correlation; and above 0.80 , very good correlation.

In order to check the predictive power of MABC-2 for identifying the DCD in children, a simple linear regression analysis was performed. The independent variable was the total score on the MABC-2 test and the de-

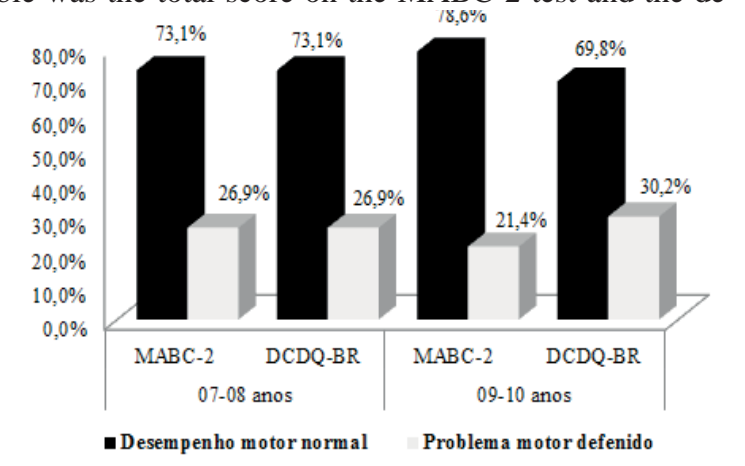

pendent variable was DCDQ-BR scores, the gold standard for identification of DCD. A p value $<0.05$ was considered statistically significant.

\section{RESULTS}

A total of 155 schoolchildren from the city of Manaus, including 81 girls with a mean age of $8.77( \pm 1.22)$ years and 74 boys with a mean age of $8.74( \pm 1.12)$ years, and 195 schoolchildren from the city Florianópolis, including 94 girls with a mean age of $9.09( \pm 1.08)$ years and 101 boys with a mean age of 8.87 ( \pm 1.06 ) years, were assessed.

Figure 1 shows the motor performance classification assessed using MABC-2 and DCDQ-BR according to sex and age group. In the assessment of the MABC-2 motor battery in the age group of $7-8$ years, $26.9 \%$ of girls and $34.4 \%$ of boys were classified as having a defined motor problem; the DCDQ -BR questionnaire yielded similar findings.

For the age group of 9-10 years, $21.4 \%$ of girls and $24.5 \%$ of boys were classified as having a defined motor problem according to MABC- 2 and $30.2 \%$ of girls and $22.3 \%$ of boys were classified as such according to DCDQ-BR (Figure 1).

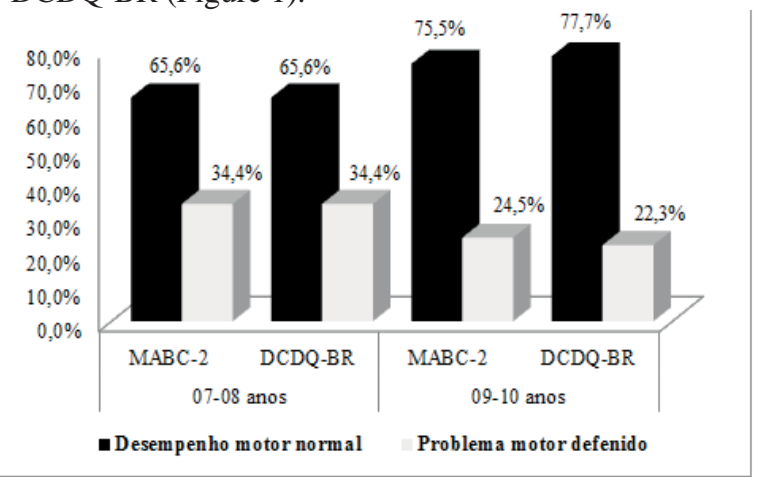

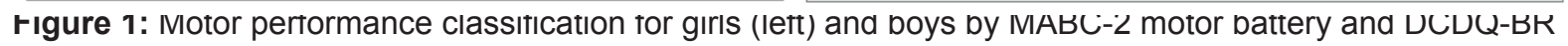
questionnaire according to age group.

When comparing the MABC-2 motor battery and DCDQ-BR for girls in the age groups 7-8 years and 9-10 years, positive correlations between total score and the standard score of MABC-2 according to the
DCDQ-BR for the age group of $7-8$ years (total, $r=0.47$; $\mathrm{p}=0.01 ;$ standard, $\mathrm{r}=0.45 ; \mathrm{p}=0.01$ ) and 9-10 years (total, $\mathrm{r}=0.32 ; \mathrm{p}=0.01$; standard, $\mathrm{r}=0.35 ; \mathrm{p}=0.01)$ was observed, respectively (Table 1 ).

Table 1: Spearman correlation coefficient for female students according to age group

\begin{tabular}{lcccc} 
MABC-2 & DCDQ-BR & $\mathbf{0 7 - 0 8}$ years & $\mathbf{0 9 - 1 0}$ years & \\
& p-value & DCDQ-BR & p-value \\
MABC-2 Motor Test (total score) & 0,47 & $<0,01$ & 0,32 & $<0,01$ \\
MABC-2 Motor Test (Standard score) & 0,45 & $<0,01$ & 0,35 & $<0,01$ \\
\hline
\end{tabular}

Table 2 shows the correlations between MABC-2 motor battery (total score and standard score) and DCDQBR for men aged 7-8 years and 9-10 years. The results show a significant positive correlation between total score and the standard score of MABC-2 according to the DCDQ$\mathrm{BR}$ for the age group of 7-8 years (total, $\mathrm{r}=0.62 ; \mathrm{p}=0.01$; standard, $r=0.61 ; p=0.01$ ) and 9-10 years (total, $r=0.35$; $\mathrm{p}=0.01$; standard, $\mathrm{r}=0.37 ; \mathrm{p}=0.01$ ) (Table 2).

Table 2: Spearman correlation coefficient for malee students according to age group

\begin{tabular}{lccc} 
MABC-2 & $\begin{array}{c}\mathbf{0 7 - 0 8} \text { years } \\
\text { DCDQ-BR }\end{array}$ & $\begin{array}{c}\mathbf{0 9 - 1 0} \text { years } \\
\mathbf{p} \text {-value }\end{array}$ & $\begin{array}{c}\text { DCDQ-Balor } \\
\text { MABC-2 Motor Test (total score) }\end{array}$ \\
MABC-2 Motor Test (Standard score) & 0,62 & $<0,01$ & 0,35 \\
\hline
\end{tabular}


From the simple linear regression analysis, it was possible to infer the predictive ability of MABC-2 to identify the presence or risk of the development of DCD in children. The regression model showed statistically sig- nificant results for boys between the ages of 7 and 8 years and 9 and 10 years $(\mathrm{p}<0.05)$ (Table 3$)$, with the largest coefficient of determination observed for the newest $\left(\mathrm{R}^{2}=\right.$ $0.34)$ compared to older participants $\left(R^{2}=0.27\right)$ (Table 3$)$.

Table 3: DCDQ-BR simple linear regression analysis according to the total score of the MABC-2 for males participants.

\begin{tabular}{lcccccc} 
Parametric & B & $\boldsymbol{\beta}$ Standard error & $\boldsymbol{\beta}$ standard & $\boldsymbol{p}$ value & $\mathbf{R 2}$ & Model $\boldsymbol{p}$ value \\
Constant & 25,61 & 6,40 & $7-8$ years & $<0,001$ & & $<0,001$ \\
MABC-2 total score & 0,45 & 0,09 & 0,52 & $<0,001$ & 0,34 & \\
& & & $9-10$ years & & & \\
Constant & 20,39 & 6,38 & - & 0,002 & & $<0,001$ \\
MABC-2 total score & 0,53 & 0,09 & 0,58 & $<0,001$ & 0,27 & \\
\hline
\end{tabular}

Note: B: better grip line slope; $\beta$ : for better grip line slope in standard deviation; R2: explained variance / coefficient of determination; $\mathrm{p}$ : level of significance.

In females, the regression model yielded statistically significant results for ages $7-8$ years and $9-10$ years ( $\mathrm{p}<0.05$ ). However, when compared to the coefficient of determination $\left(\mathrm{R}^{2}\right)$ similar values were observed for ages $7-8$ years and 9-10 years $\left(\mathrm{R}^{2}=0.10\right.$ and $\mathrm{R}^{2}=0.08$, respectively) (Table 4).

Table 4: DCDQ-BR simple linear regression analysis according to the total score of the MABC-2 for females

\begin{tabular}{|c|c|c|c|c|c|c|}
\hline Parametric & B & $\beta$ Standard error & $\beta$ standard & $p$ value & $\mathbf{R 2}$ & Model $p$ value \\
\hline Constant & 42,77 & 5,92 & - & $<0,001$ & & \\
\hline MABC-2 total score & 0,25 & 0,08 & 0,28 & 0,003 & 0,10 & 0,003 \\
\hline Constant & 44,42 & 4,97 & $9-10$ years & $<0,001$ & & \\
\hline MABC-2 total score & 0,24 & 0,07 & 0,31 & 0,001 & 0,08 & 0,001 \\
\hline
\end{tabular}

Note: B: better grip line slope; $\beta$ : for better grip line slope in standard deviation; R2: explained variance / coefficient of determination; $\mathrm{p}$ : level of significance.

\section{DISCUSSION}

This study contributes to knowledge in this field by demonstrating that there is a positive and significant correlation between MABC-2 and DCDQ-BR total scores, regardless of sex or age group. This suggests that DCDQBR provides a useful validity criterion, since motor performance is part of its construct, overall development disorders. This result is consistent with findings of other studies conducted in children aged 5-15 years ${ }^{13,22}$ that generated similar results $(\mathrm{p}=0.01)$. Schoemaker et al. ${ }^{20}$ assessed children aged 5-8 years and found smaller albeit a significant correlation between MABC and DCDQ $(\mathrm{r}=0.36$; $\mathrm{p}<0.001)$. A smaller study of Brazilian children conducted by Capistrano et al. ${ }^{19}$ found no association between the instruments. These discrepancies may be related to methodological aspects, such as small group sizes. The present research, which includes a much larger sample of children, provides strong evidence for the concurrent validity between MABC-2 and DCDQ-BR in children from two Brazilian states.

The regression between the total punctuationof MABC-2 and DCDQ-BR scores showed evidence that general coordinative disorders in children can be in part explained by the MABC-2 motor test performance. That is, MABC-2 may explain and also predict which children can have or will have some general developmental coordination disorders, mainly between boys that presented higher determination coefficient with regards to girls. Therefore, this study provides evidence that MABC-2 can be used as an indicator for DCD. Furthermore, owing to its association with the DCDQ-Br, the MABC-2 serves as a good indicator for children with general coordinative disorders, providing a preliminary diagnosis that can be used to identify specific Brazilian children who may need specific clinical or pedagogical approaches. By using MABC-2 to identify the children with the highest risk early on, we can create opportunities for the development of appropriate intervention strategies.

Given that our results confirm findings in national and international literature, we can say with confidence that the compared instruments in this study have a good reliability. Regarding the prevalence of motor disorders according to biological sex, the results indicate agreement with global estimates of higher prevalence of motor disorders among boys ${ }^{23}$. These data are consistent with 
those from other studies ${ }^{24}$ showing higher incidence of DCD among boys. Data from the World Health Organization (WHO) indicate that motor difficulty occurs more frequently in boys (four or five boys for every girl). Confirming this predisposition in boys ${ }^{3}$ an evaluation of 380 scholars in Florianópolis/SC showed that the boys showed lower performance than girls. Green et al. ${ }^{25}$ assessed 4,331 English children, among whom 173 were considered to have motor difficulty; of these students, $60.6 \%$ were boys and $40.4 \%$ were girls.

There is no clear explanation for this higher prevalence of motor difficulty among boys in the current literature. However, Zwicker et al. ${ }^{23}$ found some evidence that low motor performance may be more common in children born with low birth weight or premature children. In addition, this study showed an increased risk of neurological damage among boys born with these conditions. As such, a higher prevalence of motor difficulty in boys may be attributable to effects in early life and infancy.

We observed that children's maturation process decreased the association between MABC-2 and DCDQ$\mathrm{BR}$. That is, the MABC-2 had better predictive power in younger children than in older children who participated in this study. With regard to motor performance classification by applying the MABC-2 motor battery and DCDQBR questionnaire, the prevalence found was the same for the age group of 7-8 years in both sexes, suggesting that, despite the methodological differences between instruments, MABC-2 is a good indicator for the diagnosis of DCD in children aged 7-8 years. These results are surprising, given that DCDQ is considered the gold standard for evaluation of DCD in this population. In males aged 9-10 years, MABC-2 classified more children with motor problem than DCDQ-BR; however, the difference was small: $<10$ percentage points.

Cardoso, Magalhães, and Rezende ${ }^{26}$ assessed 793 Brazilian children aged 7-8 years and found no differences in the DCD classification between DCDQ and MABC-
2; 34 children were considered to have DCD by both instruments. However, other studies have shown larger differences regarding the prevalence of motor problems among children between the two instruments. Pannekoek et al. ${ }^{22}$ and Capistrano et al. ${ }^{19}$ suggested that this discrepancy can be explained due to methodological aspects used in the construction of the research tools ${ }^{27}$ as well as varying cutoff points used to identify problems in different motor tests.

With regard to the fact that differences between instruments were only observed in the 9-10-year-old group, we suggest two possible explanations. The natural course of child development may decrease the strength of the associations between motor performance and general motor disorder. Alternatively, increased independence in older children may decrease the amount of time that parents and guardians spend surveilling their behavior. The DCDQ is filled out by parents or guardians, who may not play an active role in the children's daily life by the age of $7-8$ years.

The lack of sample representativeness is the main limitation of this study, which prevents extrapolation of data conclusions. Additional studies of a representative sample are required in order to confirm data obtained in the current research. Another limitation is the lack of longitudinal follow-up data to confirm the capability of MABC in predicting general developmental coordination disorders. This criterion validation can be conducted in two possible ways, either by accompanying children through their life until adolescence, or by transversely applying the same tests in children with a definitive clinical diagnosis of a developmental disorder.

\section{AKNOWLEDGEMENTS}

Fundação de Amparo à Pesquisa e Inovação do Estado de Santa Catarina - FAPESC 2015 TR 390.

\section{REFERENCES}

1. King Dowling S, Rodriguez MC, Missiuna C, Cairney J. Validity of the Ages and Stages Questionnaire to detect risk of Developmental Coordination Disorder in preschoolers. Child: Care, Health Dev. 2015;1-7. DOI: http://dx.doi.org/10.1111/cch.12314

2. Caçola P, Romero H, Ibana H, Chuang J. Effects of two distinct group motor skill interventions in psychological and motor skills of children with Developmental Coordination Disorder: A pilot study. Disabil Health J. 2015;9(1):172-8. http://dx.doi.org/10.1016/j.dhjo.2015.07.007

3. Miranda TB, Beltrame TS, Cardoso FL. Desempenho motor e estado nutricional de escolares com e sem transtorno do desenvolvimento da coordenação. Rev Bras Cineantropom Desempenho Hum. 2011;13(1):59-66. DOI: http://doi.org/10.5007/1980-0037.2011v13n1p59

4. Santos VAP, Vieria JLL. Prevalência de desordem coordenativa desenvolvimental em crianças com 7 a 10 anos de idade. Rev Bras Cineantropom Desempenho Hum. 2013;15(2):233-42. DOI: http://doi. org/10.5007/1980-0037.2013v15n2p233

5. Silva J, Beltrame TS. Indicativo de transtorno do desenvolvimento da coordenação de escolares com idade entre 7 e 10 anos. Rev Bras Ciênc Esporte. 2013; 35(1):3-14. DOI: http://doi.org/10.1590/S010132892013000100002

6. Nascimento EMF, Contreira AR, Silva EVA, Souza LPD, Beltrame TS. Desempenho motor e estado nutricional em escolares com transtorno do déficit de atenção e hiperatividade. J Hum Growth Dev. 2013;23(3):358-64. DOI: http://dx.doi.org/10.7322/jhgd.69514 
7. Silva J, Beltrame TS, Oliveira ADVPD, Sperandio FF. Dificuldade motoras e de aprendizagem em crianças com baixo desempenho escolar. J Hum Growth Dev. 2012; 22(1):41-46.

8. Engel-Yeger B, Hanna KA. The relationship between Developmental Co-ordination Disorders, child's perceived self-efficacy and preference to participate in daily activities. Child: Care, Health Dev. 2010; 6(5):670-7. DOI: http://doi.org/10.1111/j.1365-2214.2010.01073.x

9. Jarus T, Lourie-Gelberg $Y$, Engel-Yeger B, Bart O. Participation patterns of school-aged children with and without DCD. Res Dev Disabil. 2011;32(4): 1323-31. DOI: http://doi.org/10.1016/j.ridd.2011.01.033

10. Liu T, Breslin CM. The Effect of a Picture Activity Schedule on Performance of the MABC-2 for Children With Autism Spectrum Disorder. Res Q Exerc Sport. 2013;84(2):206-12. DOI: http://doi.org/10.1080/027 01367.2013.784725

11. Henderson SE, Sugden DA, Barnett A. Moviment Assessment Battery for Children-2 (2nd ed). London: The Psychological Corporation; 2007.

12. Wilson B, Dewey D, Campbell A. Developmental coordination disorder questionnaire (DCDQ). Canada: Alberta Children's Hospital Research Center; 1998.

13. Civetta LR, Hillier SL. The developmental coordination disorder questionnaire and movement assessment battery for children as a diagnostic method in Australian children. Pediatr Phys Ther . 2008;20(1): 39-46. http://doi.org/10.1097/PEP.0b013e31815ccaeb

14. Tseng MH, Fu CP, Wilson BN, Hu FC. Psychometric properties of a Chinese version of the developmental coordination disorder questionnaire in community-based children. Res Dev Disabil. 2010;31(1):33-45. http://doi.org/10.1016/j.ridd.2009.07.018

15. Kennedy-Behr A, Wilson BN, Rodger S, Mickan S. Cross-cultural adaptation of the Developmental Coordination Disorder Questionnaire for brazilian children. Neuropediatrics. 2013; 44(5): 245-51. DOI: http:// doi.org/10.1055/s-0033-1347936

16. Traub R, Levi A, Parush S. Validity and reliability of the developmental coordination disorder questionnaire for school-aged children in Israel. Isr J Occup Ther. 2005; 14(4): H175-91.

17. Nakai A, Miyachi T, Okada R, Tani I, Nakajima S, Onishi M, et al. Evaluation of the Japanese version of the Developmental Coordination Disorder Questionnaire as a screening tool for clumsiness of Japanese children. Res Dev Disabil. 2011;32(5):1615-22. DOI: http://doi.org/10.1016/j.ridd.2011.02.012

18. Prado MS, Magalhães LC, Wilson BN. Cross-cultural adaptation of the Developmental Coordination Disorder Questionnaire for brazilian children. Rev Bras Fisioter. 2009;13(3):236-43. DOI: http://dx.doi. org/10.1590/S1413-35552009005000024

19. Capistrano R, Ferrari EP, Souza LP, Beltrame TS, Cardoso FL. Concurrent validation of the MABC-2 Motor Tests and MABC-2 Checklist according to the Developmental Coordination Disorder Questionnaire-BR. Motriz: Rev Educ Fis. 2015;.21(1):100-106. DOI: http://dx.doi.org/10.1590/S1980-65742015000100013

20. Schoemaker MM, Flapper B, Verheij NP, Wilson BN, Reinders-Messelink H, Kloet A. Evaluation of the Developmental Coordination Disorder Questionnaire as a screening instrument. Dev Med Child Neurol. 2006;48(8):668-73. DOI: http://doi.org/10.1017/S001216220600140X

21. Henderson S, Sugden D. Movement Assessment Battery for Children- MABC. London: The Psychological Corporation; 1992.

22. Pannekoek L, Rigoli D, Piek JB, Barret NC, Schoemaker M. The revised DCDQ: Is it a suitable screening measure for motor difficulties in adolescentes. Adap Phys Activ Q. 2012;29(1):81-97.

23. Zwicker JG, Missiuma C, Harris SR, Boyd LA. Developmental coordination disorder: a review and update. Eur J Paediatr Neurol. 2012; 16(6):573-81. DOI: http://doi.org/10.1016/j.ejpn.2012.05.005

24. Gibbs J, Appleton J, Appleton R. Dyspraxia or developmental coordination disorder? Unravelling the enigma. Arch Dis Child. 2007;92(6):534-9. DOI: http://doi.org/10.1136/adc.2005.088054

25. Green D, Lingam R, Mattocks C, Riddoch C, Ness A, Emond A. The risk of reduced physical activity in children with probable Developmental Coordination Disorder: a prospective longitudinal study. Res Dev Disabil. 2011;32(4):1332-42. DOI: http://dx.doi.org/10.1016/j.ridd.2011.01.040.

26. Cardoso AA, Magalhães LC, Rezende MB. Motor skills in Brazilian children with developmental coordination disorder versus children with motor typical development. Occup Ther Int. 2014;21(4):176-85. DOI: http://doi.org/10.1002/oti.1376

27. Pasquali L. Psychometrics. Rev Esc Enferm USP. 2009;43(Spe): 992-9. DOI: http://dx.doi.org/10.1590/ S0080-62342009000500002

This article is distributed under the terms of the Creative Commons Attribution 4.0 International License (http://creativecommons.org/licenses/by/4.0/), which permits unrestricted use, distribution, and reproduction in any medium, provided you give appropriate credit to the original author(s) and the source, provide a link to the Creative Commons license, and indicate if changes were made. The Creative Commons Public Domain Dedication waiver (http://creativecommons.org/publicdomain/zero/1.0/) applies to the data made available in this article, unless otherwise stated. 


\section{Resumo}

Introdução: o Movement Assessment Battery for Children, Segunda Edição (MABC-2) vem sendo amplamente utilizado na literatura nacional para diagnóstico do transtorno do desenvolvimento da coordenação (TDC). Problema: A relação do MABC-2 com o instrumento padrão ouro para o TDC, a versão brasileira do Developmental Coordinatiom Disorder Questionnaire (DCDQ-BR) não está bem consolidada, apresentando controvérsias.

Objetivo: o objetivo do presente estudo foi testar o nível de congruência entre o teste motor do MABC2 com o DCDQ-BR.

Método: o processo de validação concorrente ocorreu com a participação de 350 escolares, na faixa etária de 7 a 11 anos de idade, dos municípios da grande Florianópolis-SC e Manaus-AM e seus respectivos pais ou responsáveis. A concordância entre os instrumentos foi verificada por meio do teste de correlação de Spearman e regressão linear simples no programa estatístico SPSS versão 20.0, considerando um nível de significância de 5\%.

Resultados: Foi verificada uma associação entre as escalas dos dois instrumentos de medida. Conclusão: $O$ estudo mostrou evidências de validação concorrente entre o MABC-2 e o DCDQ-BR sugerindo que o MABC-2 pode ser usado como um indicativo do transtorno do desenvolvimento da coordenação.

Palavras-chave: validação, MABC-2, DCDQ-BR, desempenho motor. 